\title{
TERRA expression levels do not correlate with telomere length and radiation sensitivity in human cancer cell lines
}

\author{
Alexandra Smirnova, Riccardo Gamba, Lela Khoriauli, Valerio Vitelli, Solomon G. Nergadze* and \\ Elena Giulotto*
}

Laboratorio di Biologia Molecolare e Cellulare, Dipartimento di Biologia e Biotecnologie "Lazzaro Spallanzani," Università di Pavia, Pavia, Italy

Edited by:

Claus M. Azzalin, ETH Zurich, Switzerland

Susan M. Bailey, Colorado State University, USA

Reviewed by:

Anna Genescà, Universitat Autònoma de Barcelona, Spain

Predrag Slijepcevic, Brunel University, UK

\section{*Correspondence:}

Solomon G. Nergadze and

Elena Giulotto, Laboratorio di Biologia Molecolare e Cellulare, Dipartimento di Biologia e Biotecnologie "Lazzaro Spallanzani," Università di Pavia, Via Ferrata 1, 27100 Pavia, Italy. e-mail: solomon.nergadze@unipv.it; elena.giulotto@unipv.it
Mammalian telomeres are transcribed into long non-coding telomeric repeat-containing RNA (TERRA) molecules that seem to play a role in the maintenance of telomere stability. In human cells, CpG-island promoters drive TERRA transcription and are regulated by methylation. It was suggested that the amount of TERRA may be related to telomere length. To test this hypothesis we measured telomere length and TERRA levels in single clones isolated from five human cell lines: HeLa (cervical carcinoma), BRC-230 (breast cancer), AKG and GK2 (gastric cancers), and GM847 (SV40 immortalized skin fibroblasts). However, these two parameters did not correlate with each other. Moreover, cell survival to $\gamma$-rays did not show a significant variation among the clones, suggesting that, in this celIular system, the intra-population variability in telomere length and TERRA levels does not influence sensitivity to ionizing radiation. This conclusion was supported by the observation that in a cell line in which telomeres were greatly elongated by the ectopic expression of telomerase, TERRA expression levels and radiation sensitivity were similar to the parental HeLa cell line.

Keywords:TERRA, telomere length, radiation sensitivity, cancer cell lines, clonal variation

\section{INTRODUCTION}

Telomeres are nucleoprotein complexes, located at the ends of linear eukaryotic chromosomes, playing an essential role in the maintenance of chromosome integrity. In mammalian cells, telomeres are composed by extended tracts of (TTAGGG)n DNA repeats and by a protein complex called shelterin. While in somatic cells telomeres shorten at a constant rate at each cell division (Harley et al., 1990), due to the inability of DNA polymerase to complete replication of the lagging strand, in germline and stem cells, telomere length is maintained by the specialized enzyme telomerase (Greider and Blackburn, 1985; Wright et al., 1996). Also in cancer cells telomere length is maintained, usually through telomerase activation (Artandi and DePinho, 2010); however, in about $15 \%$ of human cancers, an alternative telomere lengthening (ALT) mechanism operates which does not require telomerase activation. In ALT cells, telomere maintenance is due to a recombination based mechanism (Bryan et al., 1997) causing great intracellular variability of telomere length (Henson et al., 2002).

It is widely accepted that the length of telomeres is determined by the balance between the rate of shortening at each replication cycle and the rate of elongation by telomerase or ALT mechanisms. The regulation and dynamics of this equilibrium are still not fully understood: different factors seem to play a role in sensing telomere length and in modulating telomere elongation (Palm and de Lange, 2008). It has been proposed that, among these factors, telomeric repeat-containing RNA (TERRA) may contribute to telomere stability. TERRA is the product of telomere transcription, performed by RNA polymerase
II (Azzalin et al., 2007; Schoeftner and Blasco, 2008). In somatic mammalian cells (Azzalin et al., 2007; Schoeftner and Blasco, 2008) as well as in human oocytes (Reig-Viader et al., 2013), TERRA is mainly localized at telomeres suggesting the existence of posttranscriptional mechanisms retaining these RNA molecules where they are synthesized; moreover, it was shown that TERRA is regulated during the cell cycle, being lowest in late $S$ phase and peaking in early G1 (Porro et al., 2010).

Telomeric repeat-containing RNA molecules are heterogeneous in length and contain not only telomeric repeats but also a portion of the subtelomeric transcripts. In human cells, TERRA is transcribed from CpG-island promoters whose methylation levels influence TERRA expression; such promoters are located on 20 subtelomeres (Nergadze et al., 2009; Farnung et al., 2010). Although these observations suggest that TERRA may play a role, specific functions still remain to be assigned to this non-coding RNA fraction. It was shown that TERRA-like oligonucleotides inhibit human telomerase in vitro (Redon et al., 2010) and several in vivo studies indicate that TERRA levels may contribute to telomere length control. In cells derived from patients affected by the ICF syndrome (immunodeficiency, centromere instability, and facial abnormalities type I), hypomethylation of the subtelomeric regions is associated with increased TERRA levels and shortened telomeres (Yehezkel et al., 2008). In yeast, the ratlp exonuclease is known to degrade TERRA and rat $1 \mathrm{p}$ mutant strains, in which TERRA levels are increased, telomeres are shortened (Luke et al., 2008); in addition, TERRA over-expression from an artificially induced promoter seem to cause telomere shortening (Pfeiffer and Lingner, 2012). Altogether, these pieces of 
evidence suggest that TERRA may promote telomere shortening, however, recent results show that the involvement of TERRA in telomere homeostasis is more complex. The in vitro observation that TERRA is an inhibitor of telomerase was not confirmed in vivo: in human cancer cells, telomerase-mediated telomere elongation is not affected by TERRA expression (Farnung et al., 2012). It has also been suggested that the relationship between TERRA and telomere length could be mediated by chromatin reorganization at telomeres. In a recent work (Arnoult et al., 2012), TERRA expression from specific telomeres was analyzed in cell lines in which telomeres were elongated by the ectopic expression of telomerase and in a HeLa clone with naturally long telomeres. In these systems, longer telomeres seemed to be associated with lower TERRA levels and the analysis of histone composition suggested that silencing of TERRA expression at longer telomeres could be mediated by the $\mathrm{H} 3 \mathrm{~K} 9 \mathrm{me} 3$ histone variant.

To elucidate the possible relationship between TERRA levels and telomere length, in the work presented here we measured these parameters in isogenic clonal populations derived from five human cancer cell lines and in a cell line in which telomeres were greatly elongated by the ectopic expression of telomerase. In addition, since previous observations suggested that telomere length may influence the cellular response to ionizing radiation (Wong et al., 2000; McIlrath et al., 2001; Drissi et al., 2011), we analyzed $\gamma$-ray sensitivity in clones characterized by different telomere lengths and TERRA expression levels.

\section{RESULTS AND DISCUSSION}

The aim of this work was to test whether a correlation exists between telomere length and TERRA expression level and to verify if either of these factors can influence radiosensitivity.

\section{TERRA LEVEL IN HeLa CELLS OVEREXPRESSING TELOMERASE}

We initially analyzed HeLa hTR/hTERT cells, a previously established cell line in which telomeres were greatly elongated by the ectopic expression of both the RNA and of the reverse transcriptase subunits of human telomerase (Cristofari and Lingner, 2006). While in the parental cell line telomeres were on average $7 \mathrm{~kb}$ long, in hTR/hTERT cells, telomeres were up to $50 \mathrm{~kb}$ long, as determined by Terminal Restriction Fragment (TRF) analysis (Cristofari and Lingner, 2006). In Figure 1A the results of a fluorescent in situ hybridization experiment with a telomeric PNA probe are shown: the intense signals at all hTR/hTERT telomeres confirm that the transduced cell line has longer telomeres compared to its parental cell line. We then measured TERRA levels by northern blotting using a telomeric DNA probe (Figure 1B): the intensity of the autoradiographic signals in the hTR/hTERT and in the parental line were similar indicating that the total amount of TERRA was not influenced by telomere elongation. This result is in agreement with a recent finding from Farnung et al. (2012) who showed that, in a hTERT infected HeLa cell line in which telomeres were elongated, no substantial alteration in total TERRA levels was detectable.

\section{TERRA LEVELS AND TELOMERE LENGTH IN CLONES ISOLATED FROM TUMOR CELL LINES}

Since it was previously shown that in tumor cell lines telomere length can be heterogeneous (Bryan et al., 1998; Savre-Train et al., 2000), we planned to measure TERRA levels and telomere length in a number of clones isolated from different human cell lines in search of a possible correlation between these two parameters.

We isolated single clones from five human cell lines. Four of these cell lines derive from different types of tumors: HeLa, from cervical carcinoma (Scherer et al., 1953); BRC-230, from primary ductal infiltrating breast carcinoma (Amadori et al., 1993); AKG

A

HeLa

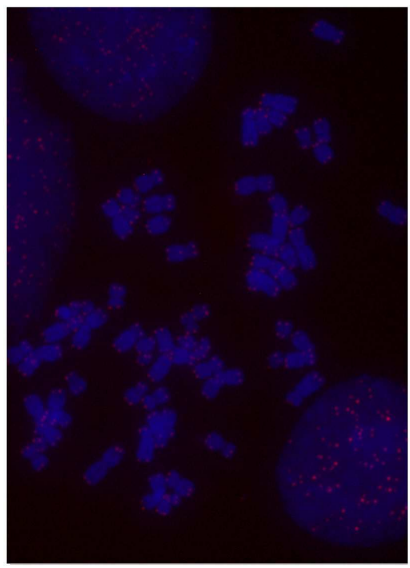

HeLa hTR/hTERT



B

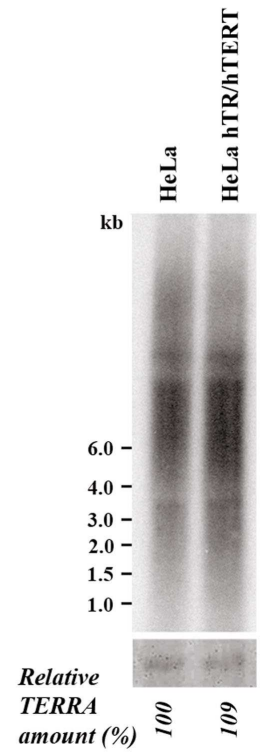

FIGURE 1 | (A) Telomere detection in HeLa and hTR/hTERT cells by PNA-FISH. Telomeric signals are in red, chromosomes are stained with DAPI. (B) Northern blot analysis of TERRA expression in HeLa and hTR/hTERT cells. Ethidium bromide-stained 18S rRNA bands are shown at the bottom. 
and GK2, from a gastric cancer pleural and an ascitic effusion, respectively (Bertoni et al., 1998). One cell line, GM847, derives from human skin fibroblasts immortalized by SV40 (Bryan et al., 1995); in this line telomerase is inactive and telomeres are maintained through the ALT mechanism. At least seven clones were isolated from each cell line; the clones were expanded until about $10^{8}$ cells, RNA and genomic DNA were then extracted. For TRF analysis the DNA was digested with the restriction enzymes RsaI and Hinfl, separated by electrophoresis, blotted to nylon membranes and hybridized to a telomeric DNA probe (Bertoni et al., 1994; Azzalin et al., 1997). Mean TRF length was measured using the densitometric method and the equation previously described (Kimura et al., 2010). Total TERRA levels were evaluated by northern blotting followed by densitometric analysis of signal intensities on the autoradiograms. In Figure $2 \mathrm{~A}$ the results of TRF length analysis of the clones and of their respective parental cell lines is shown. In the eight HeLa clones the heterogeneity in TRF average length was remarkable, ranging from 2.8 to $8.3 \mathrm{~kb}$, while TRF average length of the parental cell lines was approximately in the middle of this range. TRF length variation, comprised between 2.1 and $8.3 \mathrm{~kb}$, was also observed among the clones derived from the GK2 gastric cancer cell line and, to some extent, among those derived from the other gastric cancer line, AKG (3.1-4.8 kb). In the seven clones isolated from the breast cancer cell line BRC230 and in their parental cell line, TRFs were always rather short being ranging from 1.8 to $2.6 \mathrm{~kb}$. In all the clones derived from the GM847 cell line, most TRFs were longer than $20 \mathrm{~kb}$, however, shorter fragments, distributed over a wide range of sizes, were also detected; in the parental GM847 cell line a similar distribution of TRFs was previously described (Bryan et al., 1995). Great intracellular variation of telomere length is a typical feature of ALT cells (Henson et al., 2002) and seems to be a direct consequence of the recombination events involved in the maintenance of telomeres. The distribution of TRFs in the seven clones and in the GM847 parental line is similar (Figure 2A), however, we cannot exclude that some variation in the high molecular weight fragments may be present but is not detectable using conventional electrophoresis.

In Figure 2B the results of northern blotting experiments performed with total RNA from all the clones and from their respective parental cell lines are shown. TERRA levels were evaluated as ratio between signal intensity in each clone and in its parental cell line; these values showed inter-clonal heterogeneity, ranging from 34 to $167 \%$ in HeLa cells, from 15 to $83 \%$ in BRC230, from 33 to $129 \%$ in AKG, and from 52 to $104 \%$ in GK2

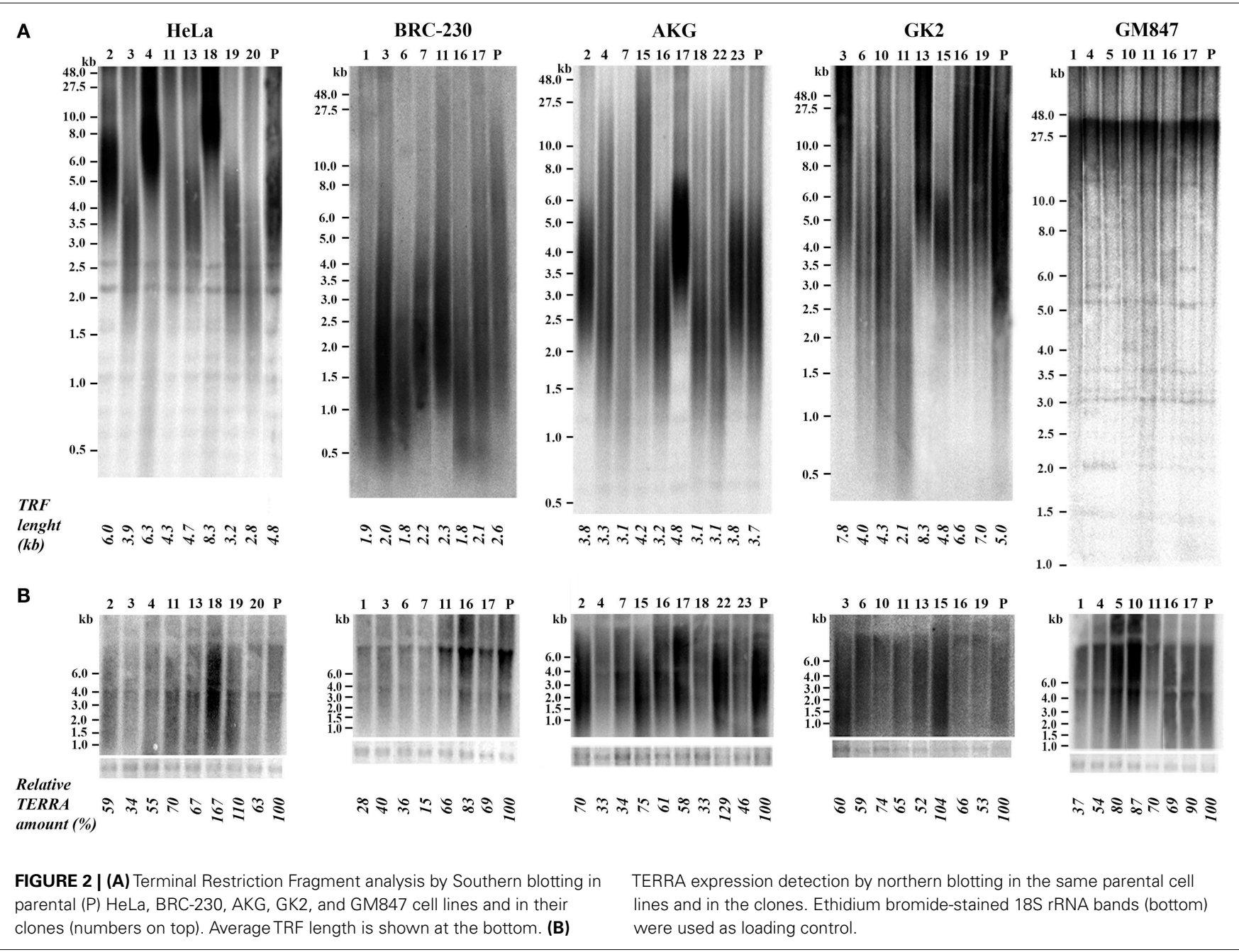


cells (Figure 2B). Also the clones isolated from the ALT cell lines GM847 showed variable TERRA levels, ranging from 37 to $90 \%$. In six of the HeLa clones, TERRA levels from specific chromosome ends were also evaluated by quantitative RT-PCR using primers for the $15 q$ and the Xp/Yp subtelomeres; the amount of TERRA in each clone was normalized with respect to the value of the parental cell line. As shown in Figure 3, TERRA expression from the two subtelomeres follows a similar trend and inter-clonal variability was observed also with this type of analysis: TERRA levels in the different clones ranged from 0.45 to 4 times those of the parental cell line. The comparison between northern blot and qRT-PCR results, indicates that telomere specific expression does not always reflect total TERRA levels; for example in the clones 11 and 13 the total amount of TERRA is very similar (Figure 2B); however, while the expression of the XpYp subtelomere in the two clones is also similar, TERRA levels from the $15 \mathrm{q}$ subtelomere are about six times higher in clone 11 compared to clone 13 . These results support the hypothesis that the regulation of TERRA expression is telomere specific, as previously suggested (Deng et al., 2012).

In Figure 4, the values of TRF length and total TERRA levels, are displayed in four scatter plots comprising data of HeLa, AKG, GK2, and BRC-230 clones, respectively. The plots show that the two parameters are independent. These results are in contrast with the previous hypothesis according to which long telomeres should correspond to low TERRA amounts. This hypothesis was initially postulated based on the observation that TERRA-like oligonucleotides inhibit human telomerase in vitro (Redon et al., 2010). However, as mentioned above, the effect of TERRA on telomerase activity was not confirmed in vivo (Farnung et al., 2012). A negative correlation between telomere length and TERRA level was also observed in ICF patients (Yehezkel et al., 2008) and in cell lines expressing exogenous telomerase or carrying naturally long telomeres (Arnoult et al., 2012).

\section{RADIATION SENSITIVITY}

In telomerase deficient mice and in cells derived from them, a clear correlation between telomere shortening and radiosensitivity was demonstrated (Goytisolo et al., 2000; Wong et al., 2000; Latre et al., 2003; Genescà et al., 2006); also in human cells in which telomerase is not expressed, such as primary fibroblasts (Drissi et al., 2011) and lymphocytes (McIlrath et al., 2001), an inverse correlation between telomere length and radiosensitivity was observed; whether this correlation holds true in telomerase positive cells is still a matter of debate. In a previous work, we showed that three telomerase immortalized fibroblast clones, characterized by different TRF length, had the same radiosensitivity (Zongaro et al., 2008), whereas radiosensitive murine lymphoma cells exhibited a sevenfold reduction in telomere length in comparison with their parental radioresistant cells (McIlrath et al., 2001). To gain new insight into this matter and to elucidate whether TERRA expression may be related to radiosensitivity, we evaluated the sensitivity to $\gamma$-irradiation in the cellular systems described above.

As shown in Figure 5A, the survival curve of HeLa hTR/hTERT cells is nearly identical to the one of the HeLa parental cell line. Therefore, in a telomerase positive background, telomere elongation due to telomerase hyper-expression does not make cells more resistant to ionizing radiations. We then measured the survival to $\gamma$-irradiation of five HeLa, five GM847 subclones, and their parental cell lines. In the five HeLa derived clones, although telomere length and TERRA expression levels were variable (Figure 2), the sensitivity to ionizing radiation was similar. The survival curves of the GM847 cell line and its five clones are also similar (Figure 5B)



FIGURE 3 | Subtelomere-specific TERRA levels in HeLa parental line (P) and six clones, determined by qRT-PCR on 15q (gray bars) and XpYp (white bars) subtelomeres. The values of HeLa parental line is arbitrarily set at 1 . Average values from three independent reactions are shown. 



\section{TRF Lenght (kb)}

FIGURE 4 | Scatter plots of TRF length versus relative TERRA amount in HeLa, BRC-230, AKG, and GK2 parental cell lines and in their clones
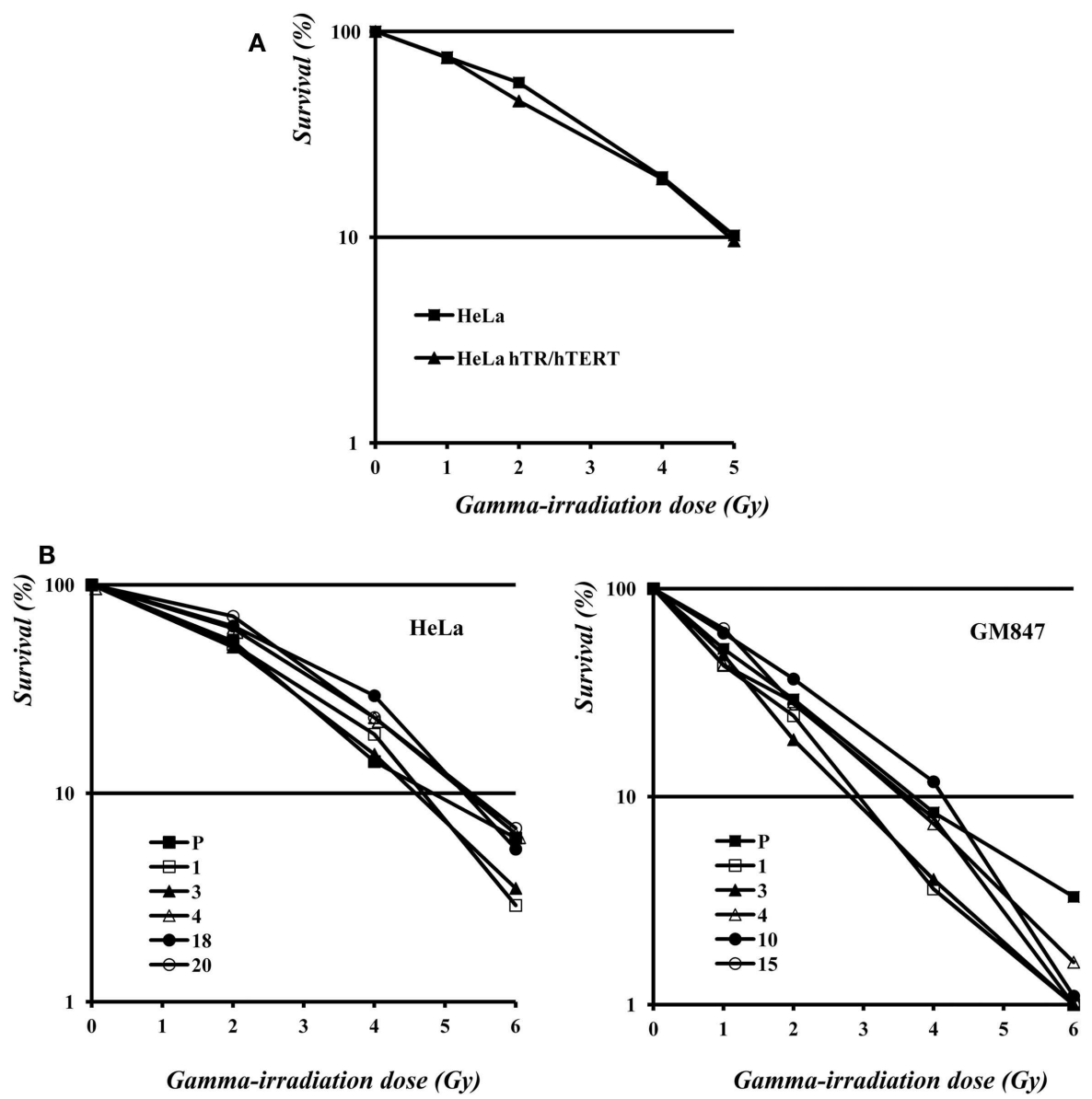

FIGURE 5 | (A) Survival to $\gamma$-irradiation of HeLa and hTR/hTERT cells. (B) Survival to $\gamma$-irradiation of HeLa (left) and GM847 (right) cells and of their clones.

suggesting that, in ALT cells as well as in telomerase positive cells, TERRA expression does not influence radiation sensitivity. However, GM847 cells are more sensitive to irradiation (10\% survival between 2 and $4 \mathrm{~Gy}$ ) than HeLa cells (10\% survival at $5 \mathrm{~Gy}$ ); this relative hypersensitivity may be related to the ALT phenotype.

\section{CONCLUSION}

In conclusion, in the work presented here we did not find any correlation between TRF length and TERRA levels in isogenic cell lines in which these parameters were naturally different. We also observed similar levels of TERRA in cells with extremely elongated 
telomeres, expressing exogenous telomerase, and in their parental cell line. Moreover, in the cellular systems exploited here, telomere length and TERRA expression are not related to alterations in the sensitivity to ionizing radiations.

\section{MATERIALS AND METHODS CELL CULTURE}

In this work we used six human cell lines: HeLa, human cervical carcinoma; hTR/hTERT, HeLa cells transduced with retroviral vectors encoding hTR and hTERT (Cristofari and Lingner, 2006); BRC-230, cell line established from surgical material of primary ductal infiltrating breast carcinoma (Amadori et al., 1993); AKG and GK2, two gastric cancer cell lines established from a pleural and an ascitic effusion, respectively (Bertoni et al., 1998); GM847, an SV40 immortalized human skin fibroblasts cell line. All cell lines were routinely cultured in $5 \% \mathrm{CO}_{2}$ at $37^{\circ} \mathrm{C}$. $\mathrm{HeLa}$, HeLa hTR/hTERT, and GM847 cell lines were propagated in Dulbecco's Modified Eagle's Media (Euroclone), supplemented with $10 \%$ Fetal Bovine Serum (Euroclone), 1\% L-glutamine (Sigma), $1 \%$ Penicillin-Streptomycin (Sigma) and 1\% non-essential amino acids (Euroclone). For BRC-230, AKG and GK2 cell lines the culture medium was composed of a 1:1 mixture of Dulbecco's Modified Eagle's Medium (Euroclone) and of HAM'S Nutrient Mixture F12 (Euroclone), supplemented with 10\% Fetal Bovine Serum (Euroclone), 1\% L-glutamine (Sigma), 1\% PenicillinStreptomycin (Sigma), and insulin $10 \mu \mathrm{g} / \mathrm{ml}$ (Sigma).

\section{RNA EXTRACTION AND NORTHERN BLOTTING}

RNA extraction from whole cells was performed using TRIzol reagent (Invitrogen) according to manufacture's protocol. To eliminate any DNA contaminations, the RNA was treated twice with RNase-free DNase I (Promega), and then purified with the RNA Clean and Concentration kit (ZYMO Research). For northern blots, $10 \mu \mathrm{g}$ of RNA were electrophoresed in $1.2 \%$ formaldehyde agarose gels and blotted to nylon membranes (Amersham HybondTM-N, GE Healthcare). The membranes were hybridized for $18 \mathrm{~h}$ in Church buffer containing ${ }^{32} \mathrm{P}-\alpha[\mathrm{dCTP}]$-labeled probes at $58^{\circ} \mathrm{C}$. The strand-specific telomeric probe used to detect total TERRA was described previously (Azzalin et al., 2007). After hybridization, the membranes were washed twice with a $2 \times$ SSC, $0.5 \%$ SDS solution for $15 \mathrm{~min}$ at $58^{\circ} \mathrm{C}$ and once with a $0.2 \times \mathrm{SSC}, 0.5 \%$ SDS solution for $30 \mathrm{~min}$ at $58^{\circ} \mathrm{C}$. Radioactive signals were detected using a phosphorimager (Cyclone, Packard).

\section{REVERSE TRANSCRIPTION AND qPCR}

Total RNA purified as described above was reverse transcribed using the RevertAid Premium First Strand cDNA Synthesis Kit (Fermentas) using the primers: (CCCTAA) $)_{5}$ at a final concentration of $0.4 \mu \mathrm{M}$ for TERRA molecules and GGAACTCGAGTTTGCGTGTCATCCTTGCGC at a final concentration of $0.04 \mu \mathrm{M}$ for U6 snRNA, used as a control.

We PCR amplified $2 \mu \mathrm{l}$ of reverse transcription reaction using GoTaq qPCR Master Mix (Promega), in a final volume of $25 \mu \mathrm{l}$. To amplify TERRA molecules, we used the following pairs of primers: CAGCGAGATTCTCCCAAGCTAAG and AACCCTAACCACATGAGCAACG for TERRA derived from the 15q subtelomere, GCAAAGAGTGAAAGAACGAAGCTT and CCCTCTGAAAGTGGACCAATCA for TERRA derived from the XpYp subtelomere. As a normalization control, we amplified U6 snRNA using GGAATCTAGAACATATACTAAAATTGGAAC and GGAACTCGAGTTTGCGTGTCATCCTTGCGC as primers. The following PCR profile was used: $5 \mathrm{~min}$ at $95^{\circ} \mathrm{C}, 45$ cycles at $95^{\circ} \mathrm{C}$ for $10 \mathrm{~s}$ and $60^{\circ} \mathrm{C}$ for $30 \mathrm{~s}$. Data were analyzed with the Opticon ${ }^{\circledR}$ Monitor 3 software.

\section{DNA EXTRACTION AND SOUTHERN BLOTTING}

Genomic DNA was extracted with phenol/chloroform standard method and purified with Proteinase $\mathrm{K}$ and Ribonuclease A (Sigma). For TRF length measurement, $10 \mu \mathrm{g}$ of high molecular weight genomic DNA were digested with the RsaI and HinfI restriction enzymes (Fermentas). After electrophoresis in $0.6 \%$ agarose gel, DNA was denatured and transferred to nylon membranes (Amersham HybondTM-N, GE Healthcare). The membranes were hybridized at $64^{\circ} \mathrm{C}$ for $18 \mathrm{~h}$ in Church buffer containing a ${ }^{32} \mathrm{P}-\alpha[\mathrm{dCTP}]$-labeled probe generated by random primer labeling of a mixture of $1-5 \mathrm{~Kb}$ long telomeric DNA fragments, prepared as previously described (Bertoni et al., 1994; Azzalin et al., 1997). After hybridization, the membranes were washed twice in $2 \times \mathrm{SSC}, 0.5 \% \mathrm{SDS}$ for $15 \mathrm{~min}$ at $64^{\circ} \mathrm{C}$ and once in $0.2 \times \mathrm{SSC}, 0.5 \%$ SDS for $30 \mathrm{~min}$ at $64^{\circ} \mathrm{C}$. Radioactive signals were detected using a phosphorimager (Cyclone, Packard).

\section{DATA ANALYSIS}

We measured TERRA amounts quantifying northern blotting signals and 18S rRNA ethidium bromide-stained bands with the software ImageJ. TERRA signals were normalized against the intensity of $18 \mathrm{~S}$ rRNA bands. For every cell line the parental line were arbitrarily set at $100 \%$. Average telomere length was determined by comparing the molecular weight of the telomeric signal with a calibration curve based on the molecular weight marker, as previously described (Kimura et al., 2010).

\section{PNA-FISH}

PNA-FISH was carried out as previously described (Ruiz-Herrera et al., 2011). Briefly, metaphase spreads were denatured at $72^{\circ} \mathrm{C}$ for $3 \mathrm{~min}$ and then hybridized with a cy3-conjugated PNA (CCCTAA) 5 probe (Panagene) in $10 \mathrm{mM}$ TRIS- $\mathrm{HCl} \mathrm{pH}$ $7.2,70 \%$ formamide and $0.5 \%$ blocking reagent (Roche). Posthybridization washes were carried out twice for $15 \mathrm{~min}$ in $70 \%$ formamide, $10 \mathrm{mM}$ TRIS- $\mathrm{HCl}, 0.1 \% \mathrm{BSA}$ at $\mathrm{pH} 7.5$, and then three times for $5 \mathrm{~min}$ in TBS buffer $(0.1 \mathrm{M}$ TRIS-HCl, $0.15 \mathrm{M}$ $\mathrm{NaCl}, 0.08 \%$ Tween $20 \mathrm{pH}$ 7.5). Chromosomes were dehydrated in ethanol, air dried and counterstained with DAPI $0.2 \mathrm{mg} / \mathrm{ml}$. Image were acquired using a ZEISS Axioplan fluorescence microscope equipped with a Photometric CCD camera and processed with IP-Lab software.

\section{SENSITIVITY TO IRRADIATION}

Exponentially growing cells were trypsinized, resuspended in complete medium and irradiated. Irradiation was carried out using a ${ }^{60} \mathrm{Co}$-ray source at a dose rate of $1.3 \mathrm{~Gy} / \mathrm{min}$. After irradiation, the cells were diluted and plated in 100-mm dishes (500 cells/plate). After 10 days, colonies were fixed, stained and the number of colonies with more than 50 cells was counted. 


\section{ACKNOWLEDGMENTS}

We thank Luca Ferretti for helpful suggestions, reagents, and instruments. We are grateful to Antonio Faucitano and Armando Buttafava (University of Pavia) for rendering available to us

\section{REFERENCES}

Amadori, D., Bertoni, L., Flamigni, A., Savini, S., De Giovanni, C., Casanova, S., et al. (1993). Establishment and characterization of a new cell line from primary human breast carcinoma. Breast Cancer Res. Treat. 28, 251-260.

Arnoult, N., Van Beneden, A., and Decottignies, A. (2012). Telomere length regulates TERRA levels through increased trimethylation of telomeric $\mathrm{H} 3 \mathrm{~K} 9$ and $\mathrm{HP} 1 \alpha$. Nat. Struct. Mol. Biol. 19, 948-956.

Artandi, S. E., and DePinho, R. A. (2010). Telomeres and telomerase in cancer. Carcinogenesis 31, 9-18.

Azzalin, C. M., Mucciolo, E., Bertoni, L., and Giulotto, E. (1997). Fluorescence in situ hybridization with a synthetic (T2AG3)n polynucleotide detects several intrachromosomal telomere-like repeats on human chromosomes. Cytogenet. Cell Genet. 78, 112-115.

Azzalin, C. M., Reichenbach, P., Khoriauli, L., Giulotto, E., and Lingner, J. (2007). Telomeric repeat containing RNA and RNA surveillance factors at mammalian chromosome ends. Science 318, 798-801.

Bertoni, L., Attolini, C., Tessera, L., Mucciolo, E., and Giulotto, E. (1994). Telomeric and nontelomeric (TTAGGG) $)_{n}$ sequences in gene amplification and chromosome stability. Genomics 24, 53-62.

Bertoni, L., Zoli, W., Mucciolo, E., Ricotti, L., Nergadze, S., Amadori, D., et al. (1998). Different genome organization in two new cell lines established from human gastric carcinoma. Cancer Genet. Cytogenet. 105, 152-159.

Bryan, T. M., Englezou, A., Dalla-Pozza, L., Dunham, M. A., and Reddel, R. R. (1997). Evidence for an alternative mechanism for maintaining telomere length in human tumors and tumor-derived cell lines. Nat. Med. 3, 1271-1274.

Bryan, T. M., Englezou, A., Dunham, M. A., and Reddel, R. R. (1998). Telomere length dynamics in telomerasepositive immortal human cell populations. Exp. Cell Res. 239, 370-378.

Bryan, T. M., Englezou, A., Gupta, J., Bacchetti, S., and Reddel, R. R. (1995). Telomere elongation in immortal human cells without detectable telomerase activity. EMBO J. 14, 4240-4248.

Cristofari, G., and Lingner, J. (2006). Telomere length homeostasis requires that telomerase levels are limiting. EMBO J. 25, 565-574.

Deng, Z., Wang, Z., Stong, N., Plasschaert, R., Moczan, A., Chen, H. S., et al. (2012). A role for CTCF and cohesin in subtelomere chromatin organization, TERRA transcription, and telomere end protection. $E M B O$ J. 31, 4165-4178.

Drissi, R., Wu, J., Hu, Y., Bockhold, C., and Dome, J. S. (2011). Telomere shortening alters the kinetics of the DNA damage response after ionizing radiation in human cells. Cancer Prev. Res. (Phila.) 4, 1973-1981.

Farnung, B. O., Brun, C. M., Arora, R., Lorenzi, L. E., and Azzalin, C. M. (2012). Telomerase efficiently elongates highly transcribing telomeres in human cancer cells. PLoS ONE 7:e35714. doi:10.1371/journal.pone.0035714

Farnung, B. O., Giulotto, E., and Azzalin, C. M. (2010). Promoting transcription of chromosome ends. Transcription 1, 140-143.

Genescà, A., Martín, M., Latre, L., Soler, D., Pampalona, J., and Tusell, L. (2006). Telomere dysfunction: a new player in radiation sensitivity. Bioessays $28,1172-1180$.

Goytisolo, F. A., Samper, E., MartínCaballero, J., Finnon, P., Herrera, E., Flores, J. M., et al. (2000). Short telomeres result in organismal hypersensitivity to ionizing radiation in mammals. J. Exp. Med. 192, 1625-1636.

Greider, C. W., and Blackburn, E. H. (1985). Identification of a specific telomere terminal transferase activity in Tetrahymena extracts. Cell 43, 405-413.

Harley, C. B., Futcher, A. B., and Greider, C. W. (1990). Telomeres shorten during ageing of human fibroblasts. Nature 345, 458-460. ger, T. R., and Reddel, R. R. (2002). Alternative lengthening of telomeres in mammalian cells. Oncogene 21, 598-610.

Kimura, M., Stone, R. C., Hunt, S. C., Skurnick, J., Lu, X., Cao, X., et al. (2010). Measurement of telomere length by the Southern blot analysis of terminal restriction fragment lengths. Nat. Protoc. 5, 1596-1607.

Latre, L., Tusell, L., Martin, M., Miró, R., Egozcue, J., Blasco, M. A., et al. (2003). Shortened telomeres join to DNA breaks interfering with their correct repair. Exp. Cell Res. 287, 282-288.
Henson, J. D., Neumann, A. A., Yea-

the irradiation source. This work was supported by grants from the European Commission Euratom (EpiRadBio), Cariplo Foundation (2008-2507), and Regione Lombardia Bando exASTIL.

Luke, B., Panza, A., Redon, S., Iglesias, N., Li, Z., and Lingner, J. (2008). The Ratlp 5' to 3' exonuclease degrades telomeric repeat-containing RNA and promotes telomere elongation in Saccharomyces cerevisiae. Mol. Cell 32, 465-477.

McIlrath, J., Bouffler, S. D., Samper, E. Cuthbert, A., Wojcik, A., Szumiel, I. et al. (2001). Telomere length abnormalities in mammalian radiosensitive cells. Cancer Res. 61, 912-915.

Nergadze, S. G., Farnung, B. O., Wischnewski, H., Khoriauli, L., Vitelli, V., Chawla, R., et al. (2009). CpGisland promoters drive transcription of human telomeres. RNA 15 , 2186-2194.

Palm, W., and de Lange, T. (2008). How shelterin protects mammalian telomeres. Annu. Rev. Genet. 42, 301-334.

Pfeiffer, V., and Lingner, J. (2012). TERRA promotes telomere shortening through exonuclease 1 mediated resection of chromosome ends. PLoS Genet. 8:e1002747. doi:10.1371/journal.pgen.1002747

Porro, A., Feuerhahn, S., Reichenbach, P., and Lingner, J. (2010). Molecular dissection of telomeric repeatcontaining RNA biogenesis unveils the presence of distinct and multiple regulatory pathways. Mol. Cell. Biol. 30, 4808-4817.

Redon, S., Reichenbach, P., and Lingner, J. (2010). The non-coding RNA TERRA is a natural ligand and direct inhibitor of human telomerase. Nucleic Acids Res. 38, 5797-5806.

Reig-Viader, R., Brieño-Enríquez, M. A. Khouriauli, L., Toran, N., Cabero, L. Giulotto, E., et al. (2013). Telomeric repeat-containing RNA and telomerase in human fetal oocytes. Hum. Reprod. 28, 414-422.

Ruiz-Herrera, A., Smirnova, A., Khoriauli, L., Nergadze, S. G., Mondello, C., and Giulotto, E. (2011). Gene amplification in human cells knocked down for RAD54. Genome Integr. 2, 5.

Savre-Train, I., Gollahon, L. S., and Holt, S. E. (2000). Clonal heterogeneity in telomerase activity and telomere length in tumor-derived cell lines. Proc. Soc. Exp. Biol. Med. 223, 379-388

Scherer, W. F., Syverton, J. T., and Gey, G. O. (1953). Studies on the propagation in vitro of poliomyelitis viruses. IV. Viral multiplication in a stable strain of human malignant epithelial cells (strain HeLa) derived from an epidermoid carcinoma of the cervix. J. Exp. Med. 97, 695-710.

Schoeftner, S., and Blasco, M. A (2008). Developmentally regulated transcription of mammalian telomeres by DNA-dependent RNA polymerase II. Nat. Cell Biol. 10, 228-236.

Wong, K. K., Chang, S., Weiler, S. R., Ganesan, S., Chaudhuri, J., Zhu, C., et al. (2000). Telomere dysfunction impairs DNA repair and enhances sensitivity to ionizing radiation. Nat. Genet. 26, 85-88.

Wright, W. E., Piatyszek, M. A., Rainey, W. E., Byrd, W., and Shay, J. W. (1996). Telomerase activity in human germline and embryonic tissues and cells. Dev. Genet. 18, 173-179.

Yehezkel, S., Segev, Y., Viegas-Péquignot, E., Skorecki, K., and Selig, S. (2008). Hypomethylation of subtelomeric regions in ICF syndrome is associated with abnormally short telomeres and enhanced transcription from telomeric regions. Hum. Mol. Genet. 17, 2776-2789.

Zongaro, S., Verri, A., Giulotto, E., and Mondello, C. (2008). Telomere length and radiosensitivity in human fibroblast clones immortalized by ectopic telomerase expression. Oncol. Rep. 19, 1605-1609.

Conflict of Interest Statement: The authors declare that the research was conducted in the absence of any commercial or financial relationships that could be construed as a potential conflict of interest.

Received: 08 March 2013; accepted: 25 April 2013; published online: 10 May 2013.

Citation: Smirnova A, Gamba R, Khoriauli $L$, Vitelli $V$, Nergadze $S G$ and Giulotto E (2013) TERRA expression levels do not correlate with telomere length and radiation sensitivity in human cancer cell lines. Front. Oncol. 3:115. doi: 10.3389/fonc.2013.00115

This article was submitted to Frontiers in Cancer Molecular Targets and Therapeutics, a specialty of Frontiers in Oncology. Copyright (c) 2013 Smirnova, Gamba, Khoriauli, Vitelli, Nergadze and Giulotto. This is an open-access article distributed under the terms of the Creative Commons Attribution License, which permits use, distribution and reproduction in other forums, provided the original authors and source are credited and subject to any copyright notices concerning any third-party graphics etc. 